\title{
Some Illustrated Comments on Designing and Conducting Problem-Based Inquiry in High Needs School Districts
}

\author{
Joseph Claudet \\ Department of Educational Psychology and Leadership, Texas Tech University, Lubbock, TX, USA \\ Email: joe.claudet@ttu.edu
}

Received 28 August 2015; accepted 20 September 2015; published 23 September 2015

Copyright (C) 2015 by authors and Scientific Research Publishing Inc.

This work is licensed under the Creative Commons Attribution International License (CC BY). http://creativecommons.org/licenses/by/4.0/

\section{c) (i) Open Access}

\begin{abstract}
This article provides an overview of the use of problem-based inquiry as a data analysis and problem solving tool to energize educators' teaching and learning improvement efforts in high needs elementary and secondary schools. Components of the problem-based inquiry method are described along with a presentation and discussion of the applied use of problem-based inquiry by collaborative teams of educators in selected elementary and secondary school case situations. The article includes examples of practical sets of actionable school improvement plans, incorporating targeted intervention programs and multiple teaching and learning improvement strategies, which educators can develop and implement as part of their problem-based data analysis and intervention design efforts.
\end{abstract}

\section{Keywords}

Problem-Based Inquiry, Instructional Teaming, School Turnaround Leadership, School Improvement

\section{Introduction}

Confronting the instructional challenges involved in responding to the multi-level learning and academic support needs of elementary and secondary school-age students who come from diverse family cultures and socioeconomic circumstances is a growing concern of school leaders in many school districts in the United States today (Gandara \& Contreras, 2009; Orfield, 2004; Rodriguez, 2014; Rumberger, 2012). These kinds of diverse students comprise a growing percentage of the total population of students in the nation's schools - a population diversity trend that is evident today as well in other countries around the world (McCowan \& Unterhalter, 2015). 
Indeed, many educators today are engaged in professional practice work in what are considered to be high needs school districts - districts containing large and continually growing multiple sub-populations of students from diverse cultural backgrounds and socioeconomic conditions with complex learning challenges and family support needs.

The growing student population diversity in today's school districts also means that educators have to navigate through more complex data to be able to identify weak areas in their teaching and learning programs. Of course, the value of scrutinizing relevant school data as a means to inform and strengthen instructional decision-making has long been recognized among educational researchers and scholar-practitioners (Blankstein et al., 2010; Earl \& Katz, 2002). However, despite this recognition, school leaders in many elementary and secondary schools in recent years have continued to struggle to find ways to creatively leverage their school's data to address the learning needs of the growing numbers of students on their campuses who are identified as "academically at-risk" (Allensworth \& Easton, 2007; Barton, 2005; Heppen \& Therriault, 2008; Jerald, 2006). Multiple approaches to managing and evaluating school learning performance data have indeed emerged in recent years promoting various data mining techniques that educators can employ to identify school teaching and learning deficiencies (Barnes \& Miller, 2001; Bernhardt, 1998; Kennelly \& Monrad, 2007; Pinkus, 2008; Robinson, Phillips, \& Timperley, 2002; Saginor, 2008). But sifting through these multiple approaches, along with attempting to accurately gauge the relative applicability and appropriateness of individual approaches in specific school contexts, has proven to be a confusing task for many school leaders - a task that often only further complicates educators' already daunting instructional improvement challenges.

The complex teaching and learning challenges facing school leaders (district and campus administrators, teachers, counselors, instructional support staff, and curriculum coordinators) in today's high needs elementary and secondary school environments require a renewed commitment by school leaders to intensify their efforts toward achieving meaningful instructional improvement gains. To properly support their instructional improvement efforts, school leaders in high needs settings need to carefully select the most powerful tools and engage in the kinds of "high leverage" teaching and learning intervention practices that have the greatest potential for yielding demonstrable learning improvement results.

One such powerful intervention tool that is receiving increasing attention by school leaders interested in accurately identifying and systematically addressing the complex teaching and learning challenges they face in their high needs campus settings is problem-based inquiry.

\section{Problem-Based Inquiry as a Flexible Tool for Energizing Learning Improvement Efforts in High Needs School Settings}

Problem-based inquiry is a data-intensive analysis and program intervention planning tool that teams of educators working in elementary and secondary school settings can use to systematize and focus their efforts in identifying and addressing student learning problems (Copland, 2003; Gaynor, 1998). A significant benefit of the problem-based inquiry approach is that educators can use this approach to develop and implement sets of meaningful, data analysis-informed program intervention designs and creative action strategies that can have real potential for directly addressing "at risk" students' complex learning challenges in high needs schools. At the center of the problem-based inquiry approach as applied in education settings is a desire to get at the root causes of students' learning problems. One unique advantage to school leaders of adopting the problem-based inquiry approach to addressing their school learning improvement challenges is that this approach provides educators with a comprehensive, integrated set of sequential logical processes to support instructional problem solving. These sequential processes can assist educators in generating new insights regarding the root causes of school learning improvement problems and help educators develop data analysis-informed strategies for addressing hard-to-analyze, entrenched student learning problem areas. Moreover, the problem-based inquiry approach is easily adaptable to varied organizational contexts. Problem-based inquiry initiatives can be conducted in a variety of school environments and settings and often include multiple components (i.e., sequential processes). These components typically involve educator teams engaging together in the following activities: 1) participating in an immersive "problem definition refinement process" using root causal data mining and analysis techniques that include the generation of iterative sets of "problem definition" research questions; 2) developing and implementing focused, problem-specific program interventions and complementary sets of creative action strategies; 3) generating comprehensive progress monitoring/adjustment plans and procedures; 4) conducting pro- 
gram intervention impact analyses.

The problem-based inquiry approach is noteworthy in that it is team-centered and data-driven. These two defining characteristics provide an integrated operational framework within which groups of educators can work together to accurately identify and address the underlying causes of persistent instructional problems. Importantly, problem-based inquiry can be used as an excellent tool to build collaborative teaming capacity among groups of educators and strengthen the data teaming cultures of schools and school districts.

\section{School Case Situations}

In the sections below I present two different "school case situations" (hypothetical scenarios based on real-world situations) in which educators are grappling with some complex and vexing teaching and learning improvement challenges in their school communities. Following each of these case presentations I describe how the applied use of the problem-based inquiry approach in each of these settings (i.e., "application in practice") can be beneficial to school leaders seeking to accurately identify teaching and learning problem areas and generate targeted intervention programs and sets of practical action strategies to address student learning improvement needs.

\subsection{Teacher Team Immersion in Problem-Based Inquiry as a Means to Identify and Address the Unique Learning Improvement Needs of Diverse, Underserved Student Populations}

Immersing educators (teachers, counselors, instructional coaches, campus curriculum coordinators, etc.) directly in the kinds of intensive, data-driven collaborative teaming and decision-making processes that constitute central defining features of the problem-based inquiry approach to student learning improvement can be one proactive means by which elementary and secondary school leaders can initiate a long-term, positive process of jumpstarting and reinvigorating student learning needs identification and assessment on their campuses. As educators evolve in their understandings of the data-driven collaborative teaming and decision-making processes that are integral components of the problem-based inquiry approach and begin to experience positive teaching and learning "payoffs" that they can derive through actively participating in these processes, educators will continue to develop steadily increasing "ownership" in the problem-based inquiry methods themselves. Importantly, educators' collective involvement in these data teaming processes will enable them to generate multiple "data analysis-informed" targeted intervention programs that can result in positive learning improvements for all learners.

As the following case situation illustrates, involving teachers directly in comprehensive grade-level data teaming and analysis activities can be particularly helpful in school community situations in which school leaders are struggling to find creative ways to meet the multiple learning needs of diverse, underserved students.

\subsubsection{Case Situation: Instructional Turnaround Challenges at Guadalupe Elementary School}

As a means to examine the potential of employing problem-based inquiry as an effective data teaming and intervention tool to help focus educators' efforts in identifying and addressing students' learning improvement needs, consider the following school case situation. Guadalupe Elementary School is one of ten elementary campuses serving a diverse population of approximately 200,000 in a large city school district located in the southwest region of Texas. At Guadalupe Elementary School there are numerous challenges for campus educators in addressing the complex learning and support needs of this kindergarten through fifth grade (K-5) campus's disadvantaged and marginalized students. Nearly half of the Guadalupe Elementary School's 400 students are classified by the state as "at risk", approximately $90 \%$ are "economically disadvantaged", and more than a third of the school's students have limited proficiency in the English language (i.e., are "limited English proficient"). Dr. Consuelo Perez (pseudonym) is in her first year as principal of Guadalupe Elementary School, having moved to this school district from another part of the state. Dr. Perez has considerable experience as a campus turnaround leader, having achieved some impressive school improvement results at her previous campus. Dr. Perez was hired by the superintendent specifically to provide some needed "data-driven turnaround leadership" to help get Guadalupe Elementary School on track and moving forward.

Dr. Perez recognized early-on during the initial months of her first year at Guadalupe Elementary that teachers at this campus are facing significant challenges in being able to find creative ways to address the comprehensive multicultural learning needs of the school's large percentages of disadvantaged and marginalized students. Notably, the Hispanic and low socioeconomic sub-populations of students at this campus are underper- 
forming compared to other student sub-groups (e.g., White/Anglo, middle/high socioeconomic populations) in Reading/English Language Arts and Mathematics. For one thing, it is already evident to Dr. Perez that teachers at Guadalupe (many of whom are Anglo teachers, with wide variability existing within this teacher group in the number of years of elementary-level classroom teaching experience that individual teachers have accumulated in highly diverse, high needs elementary school settings) have not yet developed detailed "systematic procedures" for examining student data on an ongoing basis. This is a deficit condition that Dr. Perez realizes has been a significant factor in contributing to and explaining the school's multi-year record of inadequate academic performance levels and low accountability ratings. Without clearly defined and sensible procedures for examining student learning progress data coupled with well-developed processes for leveraging the results of these data examinations to inform teachers' ongoing instructional planning and classroom teaching practices, Dr. Perez knows that teachers are missing important opportunities for identifying and addressing students' specific "learning needs"- both for student sub-groups and for individual students. Dr. Perez is also aware that Guadalupe students' reading and math learning performance (particularly Hispanic and low socioeconomic student sub-groups) as documented on the school's annual accountability report card is significantly below state and regional performance levels in Reading/English Language Arts and Mathematics subject categories. Guadalupe Elementary School's accountability report cards over the past several years, in particular, have continued to spotlight the school's consistently low performance ratings on important Texas Academic Performance Report (TAPR) campus-level indices - notably on TAPR accountability index 2 (Student Progress) and TAPR accountability index 3 (Closing Performance Gaps). In view of these low performance levels, Dr. Perez is concerned that teachers' instructional practices at Guadalupe Elementary, especially in the areas of reading and mathematics, may not yet be "student-customized" in ways that enable teachers to comprehensively address Guadalupe students' unique "multicultural" learning support needs. Dr. Perez knows from experience that many elementary schools that have large, diverse multicultural student populations often flounder in their efforts to address their students' learning needs because educators in these elementary schools have not yet taken the time and expended the effort needed to develop the appropriate "multicultural curriculum" and "multicultural learning assessments" necessary to be able to be genuinely culturally responsive to these students. To make matters even worse, the district has a disappointing record over the past several years of a rather haphazard and inconsistent implementation of the Professional Learning Community (PLC) teacher learning and development model throughout the district's elementary campuses. As a result, teachers at Guadalupe Elementary have been-and are continuing to be-decidedly resistant to the additional work demands and pressures that "PLC implementation" is placing on them.

Also, in addition to spending considerable time observing and reflecting on teachers' current data use and instructional planning and teaching practices at her new school assignment, Dr. Perez has already noticed in the few months she has been at Guadalupe that parental involvement in school community activities is very low. From her administrative experience in her previous school setting, Dr. Perez is well aware that parents of English as a Second Language (ESL)/English Language Learner (ELL) students are often less involved in school curricular program activities (such as attending school open-house events and parent-teacher association [PTA] meetings, and participating in school celebrations) because these parents - many of whom are Spanish-speaking only - are already overwhelmed with the everyday challenges associated with their own work and family support activities, including providing/caring for younger children, handling job and medical appointments, etc. Thus, Dr. Perez's detailed observations to date of current teacher instructional practices and parental involvement levels at her new school make it clear to her that this school's "instructional improvement challenges" are doubly compounded by the even larger (and daunting) "school community turnaround" challenge which she, as the campus's administrative and instructional leader, faces at Guadalupe Elementary. With information in hand and a solid grasp of her new school's instructional improvement challenges, Dr. Perez begins to ponder her even larger Guadalupe Elementary "school community turnaround" challenge: how to provide appropriate resources, professional development, and motivational support to her teachers to get them actively involved in building school-home liaison programs to provide focused learning support to the school's high percentage of disadvantaged and marginalized students and their families.

The collective set of school turnaround leadership issues existing at Guadalupe Elementary School presents this principal and her campus educator colleagues with some difficult challenges. But these challenges also provide an intriguing opportunity for these school leaders to engage in some focused data teaming and associated learning intervention development work through adopting a problem-based inquiry approach. From a school 
turnaround leadership perspective, the principal and her campus educator colleagues have to begin thinking about two important dimensions of their overall school improvement challenges: first, they must begin thinking intently about the kinds of inhibiting factors, obstacles, and roadblocks that they, as collaborative school leaders, must confront to effectively address the complex instructional and learning improvement needs of their school's large population of disadvantaged and marginalized students (particularly in the areas of reading and math); and second, they must also ponder how to best approach Guadalupe Elementary School's even larger school community improvement challenge of providing the kinds of creatively designed "school-to-home learning and social support" initiatives that they know will need to be an essential dimension of any comprehensive, workable plan for addressing the unique learning support needs of Guadalupe students.

\subsubsection{Application in Practice: Employing Problem-Based Inquiry to Create Culturally Responsive Learning Opportunities at Guadalupe Elementary School}

School principals seeking to leverage their school performance data to address the targeted learning needs of their students can work collaboratively with department- and grade-level teams of teachers to take very specific practical actions to address the "achievement gap/cultural responsiveness" instructional challenges at their campuses. Instructional challenges in the areas of reading and math learning often constitute two critical teaching and learning improvement need areas in many schools. And, interestingly, the reading and math student learning challenges educators confront on their campuses are frequently reflective of an underlying "student reading comprehension" root causal problem base. Through adopting a problem-based inquiry approach to identifying and addressing student learning improvement challenges, school leaders confronting these kinds of reading and math instructional challenges on their campuses can involve teachers directly in data-driven instructional teaming practices that can produce substantial teaching and learning improvement dividends. These instructional teaming practices engage teacher teams in using systematic "drill down data mining and analysis" techniques (utilizing students' written classroom and homework submissions, pre-test data, formative assessment/benchmark data, and ongoing progress monitoring data) that can lead to the development of specific multiculturally sensitive and responsive instructional planning and targeted intervention strategies to address their students' identified learning needs. As a specific example of these kinds of data-driven instructional teaming strategies: collaborative teams of educators working systematically together can reap substantial teaching and learning improvement gains through engaging in conscious efforts to drill down on a weekly basis into their own classroom-, grade-, and school-level student performance data to analyze and pinpoint underlying root causes of students' learning problems. Interestingly, teachers do not always take the time and make the conscious efforts needed to systematically engage in careful probing and analysis of their own teaching and learning performance data. As a result, these underlying root causes (such as deficiencies in basic reading comprehension) of many students' learning difficulties — which are often not readily apparent through a surface-level analysis—can go undetected in schools. Some practical dividends to teachers (and students) of utilizing these problem-based inquiry data mining and analysis techniques in these kinds of school situations are that teachers: 1) can become actively involved in developing and implementing targeted learning improvement strategies (such as designing multiculturally sensitive "reading comprehension development" instructional materials in core content areas like reading/language literacy and mathematics); and 2) can become engaged in intensive, individualized "one-onone" student assessment and progress monitoring activities that can substantively improve students' reading comprehension and learning. Moreover, these learning improvement strategies are highly implementable and cost effective from a school budgeting and personnel leadership perspective because they do not require additional expenditures for any specially designed (and expensive) intervention programs.

These "drill down data mining" and "root causal analysis" problem-based inquiry techniques can be applied directly to the Guadalupe Elementary School case situation described above. After examining their disaggregated classroom- and grade-level data closely through utilizing "drill down" deep data digs, formulating and exploring iterative sets of increasingly more focused and data-specific "problem definition" questions, and carefully analyzing their students' weekly work submissions in conjunction with aggregate formative assessment and progress monitoring data for these students, fourth and fifth grade-level teacher teams at Guadalupe Elementary could find evidence that the kinds of instructional materials and assessments teachers are currently using in reading and math are inadequate because they do not accommodate effectively the specific English language literacy developmental needs and proficiency levels of their Hispanic and low socioeconomic students. Through engaging systematically in this kind of root causal "drill down" data analysis process, fourth and fifth 
grade teachers at Guadalupe could come to the data-supported conclusion that their overall reading and mathematics instructional practices, in fact, are deficient in the kind of multicultural sensitivity necessary to support the specific classroom instruction and family support needs of their Hispanic and low socioeconomic students. This realization, gleaned as a result of teachers' own immersion in the problem-based inquiry "root causal analysis" process, would provide a data-driven impetus for these teachers to begin focusing on developing multiple instructional materials and formative assessment "redesign projects" to be able to more effectively address their students' basic English language literacy developmental learning needs. Importantly, these redesign projects would also provide teachers with opportunities to consider how students' English language literacy development can be integrated directly with their reading and mathematics content learning. Moreover, these fourth and fifth grade teachers could decide to make their instructional materials and assessment redesign projects a central focus of their Professional Learning Community (PLC) collaborative teaming efforts for the academic year to underscore the centrality of these redesign projects as a major component of their overall problem-based inquiry driven school learning improvement efforts.

Additionally, as part of a comprehensive, multi-level data analysis regimen to identify and address root causes of student learning problems, Guadalupe teachers could also regularly scrutinize formative assessment and learning intervention data directly from individual classrooms to further inform their "data-driven" student learning improvement efforts. This could involve taking a look at the formative assessments, or benchmarks, that are given to students over the course of the year in fourth and fifth grade mathematics before the summative assessment. Of particular interest to educators here would be gleaning informed insights relating to: 1) whether there were any small incremental improvement gains realized over the course of the year; 2) did individual classroom teachers and/or grade level teacher teams develop any specific intervention or pullout plans to help struggling students in specific areas; 3) have there been any changes in the types of formative assessments being given during the most recent year in comparison with past years. Engaging in this kind of ongoing review and analysis of classroom-level formative assessment and learning intervention data (including obtaining teachers' own perceptions regarding how they think students may be responding to and benefiting from specific interventions and/or targeted learning improvement strategies) would help educators obtain additional relevant information relating to the implementation of curriculum. Moreover, this ongoing review and analysis of classroom data would also assist school leaders in accurately gauging the overall instructional improvement impact of the collective portfolio of formative assessments and learning interventions being utilized on their campus.

Importantly, as a result of Guadalupe educators' active immersion in the problem-based inquiry process-i.e., utilizing intensive data teaming and "drill down" data analysis techniques to mine and analyze classroom- and grade-level disaggregated and longitudinal student learning and assessment data to uncover the underlying root causes of students' learning improvement problems; and then leveraging these root causal analysis results to develop focused, customized learning improvement interventions to address students' targeted learning improvement needs - educators at this school would be able to design and implement a set of actionable learning improvement plans. These improvement plans could include some targeted intervention programs and associated intervention program implementation data collection and analysis activities that would have considerable promise for realizing meaningful learning improvement gains in their campus community. Intriguingly, the school community insights gleaned from their cumulative problem-based inquiry efforts would enable these Guadalupe educators to fashion an integrated set of multi-level learning improvement plans that could: 1) address at a "micro-organizational level" the specific classroom- and grade-level instructional and learning improvement challenges associated with students' multicultural language literacy and content application learning needs; and 2) also simultaneously focus more broadly at a "macro-organizational level" on implementing proactive school community involvement "family liaison" learning support structures that can extend educators' multicultural curriculum and instructional support programs to students' entire families (parents, siblings).

Guadalupe administrators and teachers could incorporate into their action plan set multiple micro-organizational level instructional and learning improvement creative strategies to address the specific multicultural learning needs of disadvantaged and marginalized students at Guadalupe Elementary and involve teachers and stakeholder colleagues in proactively working together to design specific instructional accommodations to better address all of their students' English language and math learning needs. These micro-organizational level strategies could potentially include the following: 1) conducting a Comprehensive Needs Assessment (CNA) and forming a Campus Improvement Team (CIT) if none presently exists; 2) providing teachers with targeted professional development training and resources to learn how to conduct drill down "deep data digs" to delve deep into 
their classroom data to identify the "root causes" of students' reading and math learning problems, and then use the results of these "root causal analysis data digs" to design "multiculturally sensitive" instructional materials and assessments; 3) supporting teachers in developing more diversified and "multiculturally sensitive" sets of reading and math lessons and integrating these lessons into their classroom teaching instructional practices; 4) encouraging (and finding creative ways to provide time for) teachers to engage in intensive "collaborative peer teaching" efforts to develop and integrate "multicultural instructional strategies" such as individual English Language Learner student-intensive reading level screening, diagnostic assessment, and reading coaching directly into daily reading and math classroom teaching and learning practices; 5) initiating in appropriate grade levels customized "Reading Recovery" programs, "Reading Across the Curriculum" programs, and classroomand grade-level "Immersive Language Literacy" programs that leverage peer mentoring to enhance the vocabulary and literacy competency/development of English Language Learners; 6) implementing an aggressive English Language Learner student progress monitoring program that includes multiple learning remediation opportunities so students are provided the individualized learning support they need to stay on track; 7) involving teachers actively in engaging in "peer teaching observations"; 8) conducting Instructional Focus Visit (IFV) "classroom walkthroughs" on a regular basis; 9) working to clearly communicate to teachers the "multiple learning payoffs" (instructionally and professionally) to themselves and to the students and families they serve of embracing and becoming actively involved in nurturing a dynamic "all hands on deck" Professional Learning Community (PLC) culture in their school.

To complement these micro-organizational level learning improvement strategies, Guadalupe educators could also implement at the macro-organizational level a number of school community involvement creative initiatives and strategies that extend beyond the traditional school curricular and co-curricular program offerings. These macro-organizational level initiatives and strategies could potentially include the following: 1) providing inservice training to teachers on how to communicate effectively with Latino parents/families; 2) developing a "Learning Resource Support Handbook" to give to all parents in the school—a handbook that includes the names and contact information of school and district bilingual staff whom parents can contact to assist parents with their ongoing educational concerns and learning support needs; 3 ) having teachers and school counselors visit English Language Learner students and their parents in their homes to develop "school-to-home instructional support networks" that can more directly address disadvantaged and marginalized students' (and their families') specific learning and social adjustment needs; 4) working to expand these teacher "home visits" into fully developed "school-to-home liaison programs" that provide a wide range of health and social support services to students and their families - either provided directly by school personnel (e.g., school nurse/student health director; school psychologist) or through connecting these students and their families with local and regional social service agencies; 5) developing a school-to-home "Parent Learning Resource Center" (that includes books, videos, and related learning resources) that parents can both use at the Center and check out for home use to support their children's and their own learning; 6) making sure that parents are continuously informed in both Spanish and English about their children's learning progress; 7) exploring creative ways to increase parents' direct involvement in the school's teaching and learning environment through engaging in multiple outreach activities, such as: inviting parents to give talks on their cultural traditions and experiences to students; staging a variety of school-community cultural awareness events at the campus that seek to actively value and celebrate students' and parents' cultural traditions; and encouraging parents to serve as "parent mentors" to students; 8) having teachers develop multiple creative school-community "immersive learning collaborative projects" (such as "English Language Learning Circles", "Math Learning Pods", "family culture celebrations", etc.) that actively involve students, parents and family members, and community volunteers-in socially interactive ways - in English language and math learning through creatively "integrating" English language learning in reading, writing, and math with student/family/community cultural celebrations; 9) providing child care and transportation services (through tapping the assistance of school community volunteers) so parents can more easily attend school meetings and events; 10) hosting regular potluck, math/science/reading night, and open house events to build parent-community involvement; 11) initiating "English language learning/literacy" evening programs for adult learners (parents, community members) at the school.

Importantly, these macro-organizational level school community involvement creative initiatives and strategies reflect the recognition by Guadalupe educators of the urgent need to enact a systematic "school culture transformation" in their school community in order to be able to effectively meet the learning and social support needs of their school's disadvantaged and marginalized learners - many of whom are Limited English Proficient 
(LEP) and English Language Learner (ELL) students. The entire school staff (including all Guadalupe teachers and professional support personnel) needs to become actively immersed in fully embracing the Latino culture and initiating creative ways to communicate and interact with Latino students and their families in multiple school-home-community educational and social activities. Finally, it should be noted that throughout the implementation of the above micro- and macro-organizational level intervention programs and strategies Guadalupe school leaders will be continuously engaged - as an integral component of the overall problem-based inquiry process - in collecting and analyzing relevant implementation data derived from these multiple intervention and community action initiatives. Results of these implementation data analyses will be used to guide Guadalupe educators' ongoing program implementation progress monitoring and adjustment efforts and to inform their multiple intervention program impact analyses.

Through implementing the above kinds of macro-organizational level school community involvement action strategies in concert with multiple kinds of micro-organizational level instructional and learning improvement creative strategies, educators and community stakeholders at Guadalupe Elementary will be able to enact a systematic school teaching and learning transformation that holds promise for nurturing a positive "learning success culture" that can address the learning support needs of all learners in their school community.

\subsection{Leveraging Problem-Based Inquiry to Build Effective STEM and Instructional Technology Integration Cultures in School Districts}

In many school districts in the United States today educational leaders are encountering increasing pressure from their state legislatures and state education agencies to design and implement comprehensive STEM (i.e., science, technology, engineering, and mathematics) programs in their district's schools. These demands for STEM programs and STEM-integrated learning are being fueled by the recent widely publicized development and dissemination of the Next Generation Science Standards (NGSS) (National Academy of Sciences, 2012), a comprehensive set of national science standards that focuses directly on promoting the realization of STEM-integrated science teaching and learning practices in US elementary and secondary schools. Based on a comprehensive national Framework for K-12 Science Education (National Research Council, 2011) collaboratively developed by the National Research Council (NRC), the National Science Teachers Association (NSTA), and the American Association for the Advancement of Science (AAAS), the NGSS standards articulate a vision of 21st century science learning that encourages the active use by teachers and students of available mobile digital technologies (mobile laptop computers, digital tablets, and the like) and interactive social media (Youtube, Facebook, Twitter, LinkedIn, MySpace, Pinterest, Second Life, and related kinds of internet-enabled social sharing and collaboration tools) to expand and deepen students' global, interconnected learning. In seeking to embrace this 21 st century vision of technology-integrated STEM learning, many school districts have to push the limits of their own organizational resource capacity to be able to respond adequately to the infrastructure expansion demands and instructional redesign challenges associated with effectively integrating digital technologies and social media learning tools into the district curriculum. These new challenges require that school district leaders redouble their efforts to research and make sound investments in appropriate, cost-effective network technologies, along with providing ongoing professional development to campus- and district-level personnel on cutting edge technology-integrated instructional practices, to be able to effectively support 21 st century STEM-focused and technology-integrated teaching and learning at their elementary and secondary campuses.

\subsubsection{Case Situation: Post-Secondary Readiness Performance Problems at Valverde High School}

Bolstering the rigor of the curriculum to emphasize STEM-focused and technology-integrated teaching and learning and the comprehensive college and career preparedness of students is certainly a central challenge of campus administrators and teachers in many secondary schools. As a means to examine some of the multiple interrelated forces impacting 21 st century curriculum design and instructional effectiveness that are converging to create multi-level challenges for secondary campus principals and teachers consider the following high school case situation.

Campus administrators (principal and five assistant principals) and teachers at Valverde High School, a large urban ninth through twelfth grade high school campus of 3800 students in Valverde metropolitan school district in central Texas, are currently grappling with multiple campus accountability and instructional reform challenges associated with district- and state-mandated student learning performance requirements on student endof-year assessments. This high school's "post-secondary readiness" index rating — a composite campus-level per- 
formance accountability score based on collective students' averaged test results on state core content area assessments which each school in the district receives annually from the state-has continued to remain in the range of 15 to 20 percentage points below state expectations for secondary campus performance. In addition, overall campus- and grade-level student test score results on individual core content area assessments (i.e., English Language Arts, mathematics, science, social studies) have produced some growing multi-year, longitudinal evidence that confirms that large sub-populations of students (African American, Hispanic, White/Anglo) are performing disproportionately both within and across multiple core content areas - a deficit condition which is negatively impacting Valverde educators' overall ability to perform effectively in the area of addressing students' comprehensive "post-secondary" (i.e., college and career) preparedness. After struggling during the past few years to develop effective instructional planning and assessment strategies to address the multidisciplinary content learning needs of their diverse students, Valverde grade-level teacher teams have reached an impasse on how to demonstrably increase the quality of classroom teaching and learning support for their students - and do this in results-driven ways that can help their campus meet the state's STEM and instructional technology integration high school (secondary campus) accountability expectations.

\subsubsection{Application in Practice: Using Problem-Based Inquiry Methods to Reenergize STEM Learning at Valverde High School}

To address their school's complex teaching and learning challenges in a more comprehensive and integrated manner, Valverde High School leaders could explore the data-informed instructional review and program intervention development opportunities that adopting a problem-based inquiry approach to their school's learning challenges can offer. Using a systematic problem-based inquiry approach to identifying and addressing their school's multiple student content area learning and career readiness challenges, educators at this high schoolworking together as grade-level, multidisciplinary educator teams - can engage in root causal data mining and analysis techniques to zoom in on the underlying root causes of their campus- and grade-level instructional (i.e., "problem area") challenges. For example, individual multidisciplinary teacher teams in each grade level (ninth through twelfth grades) throughout the campus can decide to engage in a systematic process of collecting and analyzing their own team's aggregate sets of six-week single teacher "classroom lesson plans" and multiple teacher "interdisciplinary unit plans" for each academic year. Valverde teacher teams could use their analysis results to formulate and investigate multiple iterative sets of "problem definition" questions that emerge logically as teachers collect and scrutinize their lesson and unit plan data. This analysis process could also include engaging in a pre-intervention stage impact analysis of existing individual team instructional planning and implementation efforts through examining available disaggregated and longitudinal student learning performance data across content areas of students being served by each teacher team. Because of the diversity of teachers at this campus (in terms of total number of years teaching in secondary settings, relative experience with multidisciplinary teaming, and familiarity with mobile digital technologies and social media and their application in classroom instructional settings), teacher teams might discover as a result of their classroom lesson and interdisciplinary unit plan analyses that there are some identifiable inconsistencies in the ways both individual teachers and groups of teachers are approaching their STEM content planning, as well as discernible differences in the ways and extent to which teachers are planning for and utilizing mobile digital technologies and social media in their teaching. As a result of these collective classroom lesson and interdisciplinary unit plan analyses, Valverde teacher teams may begin to uncover some specific evidence from their collective instructional team planning practices that point to team deficiencies in the areas of "interdisciplinary, technology-integrated" instructional unit planning and learning assessment development. These deficiencies, in turn, would suggest that teachers are not receiving the kind of comprehensive, multiple content-integrated STEM and instructional technology integration professional development training and support they need to be effective in their STEM and technology integration instructional planning, learning assessment development, and progress monitoring activities. This finding, emerging directly as a result of teachers' problem-based inquiry efforts, could be used by these teachers working collaboratively with campus and district administrators to begin planning a series of targeted professional development offerings for Valverde teachers (perhaps as part of or in conjunction with similar customized professional development offerings to other secondary campuses throughout the district) that would address teachers' specific STEM-integrated inquiry and instructional technology proficiency and application needs.

Following a careful discussion of findings that emerge through engaging in root causal data mining and analysis procedures associated with the problem-based inquiry process, Valverde educators can then leverage their 
problem-based inquiry findings to begin to collaboratively brainstorm and generate a set of actionable plans (that could potentially include multiple targeted intervention programs along with ongoing opportunities to collect and analyze relevant intervention program implementation data) to address their instructional development and improvement needs. These actionable plans could conceivably include a number of STEM inquiry and instructional technology integration professional learning and organizational development strategies. First, campus administrators could work directly with teachers (as well as with district office instructional technology personnel) to jumpstart district-wide teacher professional learning through designing, developing, and piloting an ongoing series of "digital video vignettes and multimedia professional learning modules" focused specifically on developing teachers' knowledge and application proficiency levels in utilizing STEM-integrated inquiry and instructional technology integration methods. These vignettes and learning modules could be used as a means for providing ongoing professional learning resource support to classroom teachers. Importantly, these video vignettes and professional learning modules could assist educators throughout the district in gaining technical knowledge and application skill in integrating mobile digital technologies and social media into their STEM-focused classroom teaching practices. Campus-based educators could develop these "digital video vignettes and multimedia professional learning modules" through a "video recording/production lab" that they could create on their own campus (that could be supervised by some of the campus's technology-savvy teachers) with assistance from district instructional technology staff. These video vignettes and professional learning modules could be uploaded continuously onto the district's "online learning community" educational resource environment. There are a number of readily available, high-quality web-based professional development support packages such as the Annenberg Learner (2015) "Teacher Resources and Professional Development Across the Curriculum" (http://www.learner.org/) online materials and the teacher professional development tools and video resources provided by Edudemic (2015) (http://www.edudemic.com/) that can serve as excellent models for these kinds of "digital video vignette/multimedia learning module" style professional learning resources for educators. Educators could work to collaboratively develop a number of digital video vignettes and multimedia professional learning modules (perhaps showcasing the multiple ways mobile digital technologies and social media can be integrated directly into STEM-focused classroom teaching practices, interdisciplinary team planning meetings, PLC discussions, etc.) that could become initial installments contributing to the development of an evolving bank of district STEM inquiry and instructional technology integration multimedia professional learning resources for educators. The level of multiple school district personnel collaborative engagement required to develop this professional learning resource bank would itself become an integral part of the long-term professional learning dividends that could be reaped as a result of developing and disseminating these resources to assist all district educators in "retooling" and "refining" their classroom instructional practices through systematically integrating available digital instructional technologies and internet-enabled social media. Secondly, administrators and teachers could create "informal sharing" venues (blogs, micro-blogs, wikis, and other similar social networking opportunities) on the school and district "online learning community" website environment and encourage teachers to regularly share insights and solicit feedback from colleagues on their own STEM-integrated inquiry and instructional technology integration learning achievements, "instructional aha moment" discoveries, and classroom success stories.

In conjunction with the above strategies, campus administrators could encourage "instructional technology integration savvy" teachers (teachers who already have substantive experience in utilizing mobile technologies and social media in their own classroom teaching) to develop and disseminate brief testimonials on the teaching and learning dividends these teachers and their students are reaping through their active use of mobile digital technologies and social media in their classroom teaching practices. In addition, school district leaders could take advantage of potential opportunities to develop collaborative partnerships with other individual school districts - or, if feasible, even organize a "regional consortium" of multiple school districts within a state geographic region - as a means to share creative ideas and strategies for promoting technology-integrated STEM learning in their district schools. As part of district leaders' collaborative partnering efforts, multiple educator teams working together within and across districts could create and pilot a number of multidisciplinary STEM inquiry and instructional technology integration teaching and learning best practice cases demonstrating innovative, classroom-based "methods and practices" on how to effectively design, implement, progress monitor, and evaluate 21 st century "digital interdisciplinary STEM instructional units" in their schools. Furthermore, to take proactive steps toward institutionalizing the practice of engaging in problem-based inquiry (including the ongoing processes of intensive data mining and analysis of relevant data by teacher teams) in their schools, campus-level 
administrators and teachers could design and implement STEM inquiry digital "data dashboards". These data dashboards would present and archive multi-year composite, longitudinal data on both campus-wide and individual grade-level multidisciplinary teacher team efforts in: 1) completing multiple STEM inquiry and instructional technology integration professional development trainings; 2) incorporating insights gleaned from these trainings into team instructional planning and assessment development; and 3) being able to accurately assess the impact of these professional development trainings and applied instructional planning/assessment development work on students' incremental formative assessment (i.e., learning benchmarks) progress. In addition to engaging in the above creative strategies, campus-level administrators and teachers can also work proactively to involve students directly in taking an active ownership in their own technology-integrated learning. Students in today's classrooms are "digital natives" (Prensky, 2010) and are naturally enthusiastic about tapping into the "learning expansion potential" of digital learning tools. Because of this, students will jump at opportunities to become involved in working with their teachers - and also with parents, school community business and industry professionals, and other adult mentors - to collaboratively plan and implement creative "multidisciplinary STEM-focused instructional units" that will immerse students directly in leveraging mobile digital technologies and social media to expand and deepen their individual and collaborative learning. These kinds of multidisciplinary units can even involve developing "global-collaborative learning projects", in which teachers and students in two or more schools in different countries or continents might join together to design and conduct STEMfocused "problem-based learning" projects of mutual interest.

Finally, school leaders can invite area business leaders (private business entrepreneurs, industry executives, Chamber of Commerce representatives, etc.) to become involved as community-based "education stakeholder members" of the school's Campus Improvement Team (CIT) and School Improvement Steering Committee (SISC) as a creative way to engage in some dynamic "distributed leadership" development efforts (Spillane, 2006) to significantly expand school-community partnerships. Some of these business leaders could often also be parents of students currently attending the district's schools. Nurturing these kinds of community-based "collaborative partnerships" among educators and local business leaders can significantly expand the creative idea bank potential of school-level instructional teams. Specifically, these community-based "school-business" partnerships can expand the opportunities educators have for identifying targeted (i.e., "need-driven") learning intervention programs (such as regional industry-specific STEM inquiry and mobile technology integration initiatives) that are implementable at their schools. Importantly, these school-business partnerships often have the potential for generating specific "intervention program funding proposals" that will actually attract local funding to support students' learning improvement. Interestingly, community business leaders can often be very instrumental as members of campus-based "collaborative budget planning teams", bringing their unique perspective to the campus budget planning process through helping to focus campus operational budget planning committee members' efforts on "demonstrable outcomes". Business leaders can challenge school planning groups to engage in campus-based budget prioritizing and decision making practices that are highly "data-informed" and "results driven" and that are fully aligned with the school's vision and mission as a means to increase the likelihood of achieving instructional success for all students.

The above are just a few STEM-integrated inquiry and instructional technology integration professional learning and organizational development "practical strategy ideas" that school leaders (such as the administrators and teachers at Valverde High School) can consider as they work to build dynamic and enriching STEM inquiry and instructional technology integration cultures within their campuses and school districts-cultures that can positively enhance teaching and learning effectiveness for 21 st century learners. The above action strategies and intervention programs - in conjunction with ongoing data collection, analysis, and progress monitoring and adjustment efforts by school educator teams to gauge the effectiveness (intervention program impact) of these strategies and programs - when implemented effectively, can be useful in assisting all school district educators (those who are just beginning to develop their technology application skills as well as those who are already technologically savvy) in gaining deeper insight into the multiple learning payoffs for themselves and for their students of integrating digital technologies and social media into their STEM-focused instructional planning and teaching practices.

\section{Conclusion}

In this article I have sought to illustrate some of the multiple dividends that elementary and secondary school leaders (campus principals, teachers, counselors, instructional coaches, curriculum coordinators, and school com- 
munity stakeholders) can derive through utilizing problem-based inquiry as an immersive and data-driven process for realizing positive teaching and learning improvements in their school communities. The illustrative case situations discussed in this article along with the "root causal analysis" data teaming techniques, creative program interventions, and action plan strategies presented may be of interest to school leaders seeking to accurately identify and address the complex and diverse learning improvement needs of their elementary and secondary age students. Most importantly, this article seeks to illuminate the multiple instructional and school community benefits that can be realized by educators through adopting a problem-based inquiry approach to tackling their school improvement challenges - a team-centered and data-driven approach that can significantly expand opportunities in school communities for creating meaningful and enriching learning experiences for all learners.

\section{References}

Allensworth, E., \& Easton, J. Q. (2007). What Matters for Staying On-track and Graduating in Chicago Public High Schools: A Close Look at Course Grades, Failures, and Attendance in the Freshman Year. Chicago, IL: Consortium on Chicago School Research.

Annenberg Learner (2015). Teacher Resources and Professional Development across the Curriculum (1997-2015). http://www.learner.org/resources/browse.html

Barnes, F. V., \& Miller, M. (2001). Data Analysis by Walking around. The School Administrator, 58, $20-25$.

Barton, P. E. (2005). One-Third of a Nation: Rising Dropout Rates and Declining Opportunities. Policy Information Report. Princeton, NJ: Educational Testing Service.

Bernhardt, V. L. (1998). Data Analysis for Continuous School Improvement. Larchmont, NY: Eye on Education.

Blankstein et al. (2010). Data-Enhanced Leadership. Thousand Oaks, CA: Corwin Press.

Copland, M. (2003). Leadership of Inquiry: Building and Sustaining Capacity for School Improvement. Educational Evaluation and Policy Analysis, 25, 375-395. http://dx.doi.org/10.3102/01623737025004375

Earl, L., \& Katz, S. (2002). Leading Schools in a Data Rich World. In K. Leithwood et al. (Eds.), The Second International Handbook of Educational Leadership and Administration (pp. 1003-1022). Dordrecht, Netherlands: Kluwer. http://dx.doi.org/10.1007/978-94-010-0375-9 34

Edudemic (2015). The Teacher's Guides to Technology and Learning. http://www.edudemic.com/guides/

Gandara, P. C., \& Contreras, F. (2009). The Latino Education Crisis: The Consequences of Failed Social Policies. Cambridge, MA: Harvard University Press.

Gaynor, A. (1998). Analyzing Problems in Schools and School Systems. Mawah, NJ: Lawrence Erlbaum.

Heppen, J. B., \& Therriault, S. B. (2008). Developing Early Warning Systems to Identify Potential High School Dropouts. Washington DC: The National High School Center at the American Institutes for Research.

Jerald, C. (2006). Identifying Potential Dropouts: Key Lessons for Building an Early Warning Data System. Washington DC: Achieve, Inc.

Kennelly, L., \& Monrad, M. (2007). Approaches to Dropout Prevention: Heeding Early Warning Signs with Appropriate Interventions. Washington DC: National High School Center, American Institutes for Research.

McCowan, T., \& Unterhalter, E. (Eds.) (2015). Education and International Development: An Introduction. New York: Bloomsbury.

National Academy of Sciences (2012). Next Generation Science Standards: Executive Summary. Washington DC: National Academies Press. http://www.nextgenscience.org/

National Research Council (2011). A Framework for K-12 Science Education: Practices, Cross-Cutting Concepts, and Core Ideas. Washington DC: National Academies Press. http://www.nationalacademies.org/publications/index.html

Orfield, G. (2004). Losing Our Future: Minority Youth Left Out. In G. Orfield (Ed.), Dropouts in America: Confronting the Graduation Rate Crisis (pp. 131-155). Cambridge, MA: Harvard Education Press.

Pinkus, L. (2008). Using Early-Warning Data to Improve Graduation Rates: Closing Cracks in the Education System. Policy Brief. Washington DC: Alliance for Excellent Education.

Prensky, M. (2010). Teaching Digital Natives: Partnering for Real Learning. Thousand Oaks, CA: Corwin.

Robinson, V., Phillips, G., \& Timperley, H. (2002). Using Achievement Data for School-Based Curriculum Review. Leadership and Policy in Schools, 1, 3-29. http://dx.doi.org/10.1076/lpos.1.1.3.5402

Rodriguez, L. F. (2014). The Time Is Now: Understanding and Responding to the Black and Latina/o Dropout Crisis in the United States. New York: Peter Lang. 
Rumberger, R. W. (2012). Dropping Out: Why Students Drop Out of High School and What Can Be Done about It. Cambridge, MA: Harvard University Press.

Saginor, N. (2008). Diagnostic Classroom Observation: Moving beyond Best Practice. Thousand Oaks, CA: Corwin Press. Spillane, J. P. (2006). Distributed Leadership. San Francisco: Jossey-Bass Publishers. 